\title{
LA CUESTIÓN DE LO INNATO EN LA ADQUISICIÓN DEL LENGUAJE
}

\author{
Antonio Benítez-Burraco \\ Universidad de Oviedo
}

\section{RESUMEN}

Las diversas caracterizaciones que del proceso de adquisición de la lengua materna se han venido haciendo hasta la fecha pueden situarse, en líneas generales, dentro de dos marcos teóricos fundamentales: el innatista y el empirista. En la actualidad resulta posible llevar a cabo una crítica más fundada de este último (que parece corroborar su incapacidad para explicar adecuadamente las condiciones en las que se produce la ontogenia lingüística), así como una validación más precisa del primero (que parece, asimismo, confirmar la hipótesis de que nacemos dotados de una capacidad innata para adquirir el lenguaje), merced a la consideración de las evidencias empíricas y las propuestas teóricas surgidas en los últimos años acerca de este proceso. Entre las primeras cabría mencionar numerosos datos de índole genética y molecular (aunque también la importante reevaluación que, al hilo de los mismos, y desde el dominio de la Biología, se ha hecho del propio concepto «innato»); entre las segundas, diversas teorías aparecidas recientemente en el campo de la Lingüística (en buena medida de la consideración de este tipo de evidencias) y de las que el Programa Minimalista chomskyano sería la más relevante.

Palabras clave: adquisición del lenguaje, innatismo, empirismo, datos biológicos, Programa Minimalista.

\section{Abstract}

When describing and characterizing language acquisition two main theoretical frames, namely nativism and empiricism, usually compete each with the other. For instance, according to Chomsky's standard account of language, we are endowed with an innate linguistic knowledge, irreducible to other cognitive systems, which could be properly described either as a Universal Grammar [UG] (lexicon, rules, components) or as a language acquisition device [LAD]. On the other side, empiricist approaches to language acquisition suggest that language would emerge as a result of inductive learning, which is ultimately feasible because we are endowed with a more general (and innate) device for learning. As discussed, empiricist approaches cannot seemingly properly explain language acquisition, and specifically those concerns related to the so-called «argument from poverty of the stimulus». But a comprehensive nativist account of language acquisition should also be improved, in order to take into account (a) recent nativist proposals, like chomskyan Minimalist Program; (b) a more accurate definition of «innate»; and (c) biological data (including neuroanatomical, neurophysiological, genetic and molecular evidences).

Key Words: language acquisition, nativism, empiricism, biological data, Minimalist Program. 


\section{INTRODUCGIÓN}

La adquisición del lenguaje ha sido caracterizada como «el mayor logro intelectual que habremos de alcanzar cualquiera de nosotros en nuestra vida» (Bloomfield 1933, p. 29). Se trata, ciertamente, de un proceso complejo y fascinante, que ha sido estudiado con particular detalle (cf., por ejemplo, Crain y Thornton 1998; Crain y Lillo-Martin 1999; Guasti 2002; o Lust 2006). Sin embargo, hasta la fecha no ha sido posible proponer un marco teórico consensuado que describa de forma satisfactoria la ontogenia lingüística. Por un lado, la consideración de numerosas evidencias de carácter fundamentalmente lingüístico, concernientes al modo en que tiene lugar el proceso, así como a las propiedades del input que lo elicita y del que depende, ha llevado a sugerir que la adquisición del lenguaje sólo sería posible merced a la existencia de un conocimiento gramatical (más o menos elaborado) de carácter innato. Por otro lado, existen también multitud de datos, igualmente significativos, que parecen indicar que, a diferencia de lo que sucede con los sistemas comunicativos de otras especies, en el caso del lenguaje humano la experiencia desempeñaría un papel crucial en su adquisición, lo que ha llevado a proponer que el proceso se produciría merced a diversas estrategias generales de aprendizaje, que supuestamente verían facilitada su actuación por determinadas características de los datos lingüísticos que los niños han de procesar (carácter simplificado, presencia de correcciones, etc.). En este trabajo se evalúa críticamente la capacidad descriptiva de ambos tipos de hipótesis, que han venido a caracterizarse, respectivamente, como innatistas y empiristas. Si bien las tesis innatistas parecen constituir el modelo teórico más apropiado para caracterizar el proceso de adquisición del lenguaje, lo cierto es que su adecuada consideración demandaría, asimismo, (a) un examen crítico de las propuestas más recientes en este sentido, como el Programa Minimalista chomskyano; (b) una reevaluación del propio concepto «innato»; y (c) el concurso de nuevas evidencias que contribuyan a su validación, esta vez de carácter necesariamente biológico.

\section{El CARÁcter INNATO DEL LENGUAJE: PRINCIPALES EVIDENCIAS}

Desde una aproximación eminentemente lingüística al problema de la caracterización anatomofisiológica del lenguaje humano y al de su proceso de adquisición, Chomsky $(1975,1986)$ ha defendido tradicionalmente la idea de que existiría una Gramática Universal innata, esto es, determinada biológicamente. El lenguaje humano haría uso de esa Gramática, definida como una herramienta que nos lleva a clasificar palabras en categorías (gramaticales) y a organizarlas en sintagmas, para la comunicación de información de diferente naturaleza, si bien, desde 
el punto de vista que nos ocupa, lo relevante sería el hecho de que los elementos definitorios de la misma (lexicón, reglas sintácticas, etc.) descansarían sobre un conjunto de mecanismos neuronales cuyo desarrollo se encontraría programado genéticamente (Chomsky 1986). Hasta la década de los años noventa del pasado siglo, la idea que Chomsky tenía de esta Gramática Universal era la de un sistema de conocimiento autónomo basado en categorías y principios irreductibles a los de otros sistemas cognitivos (Lorenzo 2006, p. 99), si bien su pensamiento ha ido evolucionando progresivamente hacia lo que podría denominarse un innatismo sin Gramática Universal o un innatismo general (O'Grady 2003), aunque sin renunciar por completo a la posibilidad de que determinados aspectos de la facultad del lenguaje deriven de principios específicos de dominio, esto es, de aquella Gramática Universal (v. infra).

Desde Chomsky (1957) el carácter innato del lenguaje se ha aducido como explicación de fenómenos lingüísticos muy significativos y aparentemente disímiles, entre los que pueden citarse los siguientes:

a) La consecución de una capacidad lingüística plena durante la ontogenia a pesar de la «pobreza del estímulo lingüístico» que pueda rodear al niño durante su desarrollo; o dicho de otra forma, la consecución de un sistema capaz de generar e interpretar infinitas estructuras potencialmente informativas a partir de una experiencia que tiene un carácter finito, lo que parecería descartar la posibilidad de que la adquisición de dicha competencia lingüística se debiera a un proceso exclusivamente inductivo.

El argumento de la «pobreza del estímulo», propuesto también inicialmente por Chomsky (1980, p. 34), constituye una de las piedras angulares del innatismo lingüístico, por cuanto implica que la capacidad de aprendizaje del lenguaje con la que nace el individuo incluye un conocimiento más o menos detallado (y esto será objeto de controversia) acerca de hechos contingentes relativos a las lenguas naturales. Como detallan de forma particularmente precisa Pullum y Scholz (2002), este argumento se basa, por un lado, en diferentes asunciones acerca del propio proceso de adquisición de la lengua materna, concernientes, en particular, a su significativa (a) velocidad (la adquisición tiene lugar a una velocidad inusualmente alta); (b) fiabilidad (la adquisición termina produciéndose de forma efectiva en todos los casos, salvo en los patológicos); (c) productividad (la capacidad lingüística que se adquiere permite generar y comprender un número ilimitado de oraciones); (d) selectividad (la gramática finalmente adquirida es a priori una más entre otras muchas alternativas, que, sin embargo, resultarían erróneas); (e) indeterminación (la teoría gramatical finalmente desarrollada nace de un conjunto de datos intrínsecamente indeterminados); (f) convergencia (las gramáticas adquiridas por todos los miembros de una determinada comunidad de habla son similares); y (g) universalidad (los sistemas gramaticales adquiridos en el seno de cualquier comunidad de 
habla comparten semejanzas sustanciales). Pero, del mismo modo, el argumento de la «pobreza del estímulo» también descansa sobre determinadas características del propio estímulo lingüístico que elicita dicha adquisición, en particular, su carácter finito, idiosincrásico (esto es, diverso), incompleto (en el sentido de que existirían numerosas oraciones que el niño nunca oye) y degenerado (de modo que contendría diversos tipos de errores), así como en el hecho de que no incluya ningún tipo de recompensa (lo que descartaría que la adquisición del lenguaje pudiera considerarse un proceso de aprendizaje condicionado), ni tampoco ninguna clase de especificaciones negativas (esto es, de indicaciones acerca de qué construcciones son agramaticales). Este último aspecto reviste una particular trascendencia, desde el momento en que, en ausencia de este tipo de especificaciones, no parece posible llegar a conclusiones fidedignas acerca de la gramaticalidad de las construcciones partiendo de un input con las características de aquel al que se ve expuesto el niño (Fodor y Crowther 2002). En su formulación más restrictiva, el argumento de la «pobreza del estímulo» propone que el individuo alcanza determinados conocimientos sobre la estructura de su lengua (esto es, establece determinados principios o reglas gramaticales) para los que no existen evidencias en los datos que recibe durante el proceso de adquisición de la misma (Hornstein y Lightfoot 1981, p. 9; Lightfoot 1982).

La «pobreza del estímulo» se ve particularmente acentuada en el caso concreto de la lengua de signos que desarrollan de forma espontánea los niños sordos (en inglés, homesign) en ausencia de un modelo convencional pleno de lenguaje oral o sígnico, la cual presenta, sin embargo, las propiedades estructurales características del lenguaje natural, incluyendo la categorización de los signos que la integran y su combinación de forma sistemática para constituir secuencias complejas que deben describirse con toda propiedad como oraciones, en las que pueden detectarse además signos evidentes de recursividad, así como las huellas generadas por el movimiento de determinados constituyentes (Goldin-Meadow y Mylander 1990). Un caso extremo de esta situación lo constituye la Lengua Nicaragüense de Signos, que ha sido el resultado de un incremento progresivo de la complejidad lingüística del medio de comunicación empleado por una comunidad de niños sordos en ausencia de un modelo convencional de lenguaje (de modo que dicha lengua se ha generado a partir de las contribuciones de cada individuo a la comunidad de habla en forma de su propio homesign) (Senghas 1995; Kegl y otros 1999).

b) La existencia de casos en los que la adquisición del lenguaje se produce en ausencia de un input perceptivo directo, como sucede con los niños ciegos capaces de distinguir matices semánticos asociados a términos visuales (como los que diferencian a los verbos mirar y ver) 
(Landau y Gleitman 1985), o con los individuos sordociegos, que son capaces de adquirir un lenguaje a través de las vibraciones producidas en la zona del cuello y la cara, y que perciben mediante el sentido del tacto (Smith 2002).

c) La existencia de etapas del desarrollo lingüístico que se producen en ausencia de estímulos externos, como sucede, por ejemplo, con la fase de balbuceo (oral) que se advierte en individuos que son sordos de nacimiento (Locke 1983, p. 27).

d) La existencia y la operatividad desde el momento del nacimiento (e incluso, con anterioridad al mismo) de mecanismos encaminados a la discriminación y clasificación de los elementos que constituyen el flujo continuo del habla al que se ve expuesto el niño, así como a la «representación de las señales que integran el input lingüístico» (Lust 2006, p. 109), lo que sugeriría que el niño podría disponer, en general, de una capacidad biológica (esto es, innata) para distinguir determinadas propiedades de los estímulos lingüísticos que recibe en los diferentes estadios de desarrollo que va atravesando durante sus primeros años de vida.

e) El hecho de que la emergencia del lenguaje durante el desarrollo del individuo se produzca siguiendo un patrón recurrente, lo que permite, por otro lado, que todos los seres humanos categoricen de forma sustancialmente semejante su entorno lingüístico, a pesar de la significativa variabilidad de la experiencia lingüística experimentada durante su crecimiento (Anderson y Lightfoot 2000). Este patrón es también muy semejante al que caracteriza a las variantes más anómalas del proceso de adquisición, esto es, a aquellas en las que el input lingüístico es particularmente deficiente, como sucede con el homesign mencionado anteriormente (Goldin-Meadow y Mylander 1990).

f) La marcada similitud que la Lingüística descriptiva ha advertido entre todas las lenguas del mundo; o dicho de otro modo, la (cuasi) universalidad del diseño de la gramática.

g) La acentuada semejanza que existe entre lenguajes humanos que superficialmente parecen muy distintos, como las lenguas habladas y las de signos, pero que, sin embargo, presentan acusadas semejanzas en su organización, ontogenia y control neuronal (Anderson 1993). Se ha comprobado, en particular, que el lenguaje de signos y el lenguaje convencional (oral) comparten patrones de activación cerebral semejantes (Neville y otros 1998) y que los daños cerebrales tienen efectos muy parecidos en ambos casos cuando afectan a las mismas regiones (Hickok y otros 1996).

h) La independencia que parece existir aparentemente entre la función comunicativa del lenguaje y la estructura de la gramática, en contra de las tesis funcionalistas (cf. Givón 1979).

i) El hecho de que todas las lenguas de contacto terminen convir- 
tiéndose en lenguas plenas (lenguas criollas) cuando funcionan como input lingüístico para una nueva generación de hablantes (Lefebvre 1998; Bickerton 1999).

j) Finalmente, la incapacidad de mecanismos de adquisición alternativos a un dispositivo de adquisición del lenguaje innato -cf. LAD, language acquisition device (Chomsky 1965) - para explicar de forma satisfactoria la emergencia del lenguaje. Entre dichos mecanismos el más relevante sería el aprendizaje estadístico (o aprendizaje dependiente de los datos) y relacionado con éste, la imitación y/o la enseñanza, facilitada habitualmente por el recurso al habla del cuidador (o maternés) o por diversas clases de correcciones (esta cuestión se discutirá de forma pormenorizada en el apartado 4).

En atención a estos fenómenos y a otros semejantes, el conocimiento del lenguaje que posee el individuo adulto (esto es, la competencia lingüística, competence) podría y debería ser caracterizado, según la hipótesis del innatismo, con independencia de su uso (esto es, de la actuación, performance) y de los factores cognitivos, comunicativos o sociales que modulan y hacen posible dicho uso (Newmeyer 1997). En otras palabras: la facultad del lenguaje se desarrollaría a partir de una estimulación gramatical claramente deficiente merced a la estructura de conocimiento a priori de naturaleza estrictamente gramatical que supone la Gramática Universal (Stich 1975).

\section{El PAPEL DE LA EXPERIENCIA EN LA ADQUISICIÓN DEL LENGUAJE: PRIN- CIPALES EVIDENCIAS}

Como se apuntó brevemente en la introducción de este trabajo, no todo es innato en el lenguaje; antes bien, desde el punto de vista lingüístico casi todo en el proceso de adquisición de una lengua sugiere la importancia fundamental que también desempeñan los estímulos lingüísticos. La ausencia completa de los mismos durante el desarrollo suele impedir, de un modo u otro, la consecución de una competencia lingüística plena. Se cree que esta circunstancia es debida a la existencia de un período crítico para la emergencia del lenguaje, esto es, de un intervalo temporal netamente definido durante el cual la experiencia permite su adquisición, el cual tendría un carácter innato e irreversible (Lust 2006, p. 93). Casos como el de Genie, una niña que fue privada de casi cualquier tipo de estímulo de índole cognitiva entre los veinte meses y los catorce años de edad (Curtiss 1977), parecen corroborar la importancia de dicho período crítico, por cuanto, si bien esta niña terminó adquiriendo un vocabulario complejo y una cierta capacidad sintáctica (que le permitía componer pseudooraciones constituidas por varios elementos), lo cierto es que adoleció durante toda su vida de una incapaci- 
dad manifiesta para relacionar diferentes niveles de representación (en particular, las estructuras profunda y superficial de la oración), lo que se traducía en la ausencia en su lenguaje de dependencias estructurales y en la presencia de patrones de recursividad anómalos (Lust 2006. p. 94). Al igual que muchos de los individuos afectados por algún tipo de lesión traumática en las regiones cerebrales implicadas habitualmente en el procesamiento lingüístico, Genie hacía uso predominantemente para el mismo de diversas regiones del hemisferio derecho, lo que ha llevado a sugerir que en su caso, y tras la finalización del período crítico, se habría producido una atrofia funcional de las áreas encargadas en condiciones normales del procesamiento del lenguaje (Curtiss 1977, p. 216), aunque sin descartar tampoco que el anómalo perfil lingüístico de la niña pudiera haber estado motivado, en parte, por la ausencia casi completa de otros estímulos cognitivos, además de los estrictamente lingüísticos durante el desarrollo y/o que pudiera haber presentado algún tipo de retraso mental y/o haber sufrido alguna clase de daño cerebral con anterioridad a su confinamiento o durante el mismo (Lust 2006, p. 95). Por otro lado, incluso en los casos en los que se habla de desarrollo espontáneo del lenguaje o de adquisición en ausencia de un modelo convencional de éste, como los reseñados en el apartado anterior, lo cierto es que el lenguaje no se crea de la nada, sino que resulta de la linealización y de la composición de los elementos recibidos del ambiente (en el caso concreto del homesign, de los gestos realizados por la madre, a pesar de su carácter manifiestamente deficiente) (Goldin-Meadow y Mylander 1990). En definitiva, en ausencia de una comunidad de habla (o sígnica), el sistema comunicativo individual nunca alcanza el grado de complejidad que asociamos convencionalmente al lenguaje (Singleton y otros 1993).

Del mismo modo, se ha aducido como una prueba que confirmaría la hipótesis de la existencia de dicho período crítico el hecho de que los individuos adultos que tratan de aprender una segunda lengua (L2) casi nunca logren alcanzar la competencia característica de un hablante nativo. Presumiblemente lo que sucede en estos individuos es que, al haberse cerrado ya en ellos el período crítico, no serían capaces de acceder a la Gramática Universal durante el proceso de adquisición de la L2, lo que resultaría imprescindible para que dicha adquisición se consiguiera plenamente (Schacter 1990). No obstante, se ha cuestionado la validez universal de esta afirmación, por cuanto existe constancia de numerosos individuos adultos que terminan adquiriendo una competencia plena en una determinada L2, careciendo de acento alguno y siendo capaces de aprehender las distinciones fonológicas características de la misma (Lust 2006, p. 96). Parece, por consiguiente, que la experiencia desempeñaría también un papel relevante en este hecho, en el sentido de que la mayor o menor capacidad para aprender una segunda lengua 
durante la etapa adulta dependería, en gran medida, del modo en que se hubiera producido el desarrollo cerebral durante las primeras etapas de vida, así como de los estímulos lingüísticos que se hubieran recibido durante ellas (Mayberry y otros 2002). De hecho, desde el momento del nacimiento los niños son sensibles a los estímulos de carácter lingüístico presentes en el medio, los cuales son capaces de distinguir de forma selectiva frente a otros tipos de estímulos auditivos (Colombo y Bundy 1983). Del mismo modo, los niños logran distinguir desde muy pronto su lengua materna de otras lenguas que les resultan extrañas (Hesketh y otros 1997), habiéndose sugerido que esta capacidad podría aparecer antes incluso del nacimiento (DeCasper y Spence 1986).

Por otro lado, y desde un punto de vista neuronal, se sabe que la organización definitiva de los centros corticales viene condicionada en gran medida por la experiencia. La plasticidad neuronal, que permite responder estructural y funcionalmente a los cambios producidos en el ambiente, es una propiedad intrínseca de la mayoría de los circuitos que integran el cerebro humano y, consecuentemente, influye sustancialmente en el proceso de emergencia y en el funcionamiento de los centros implicados en el procesamiento lingüístico, haciendo que la compleja arquitectura neuronal que parece ser responsable del mismo (para una revisión, v. Benítez-Burraco 2005) diste mucho de tener un carácter invariable, ni en modo alguno sea idéntica en el momento del nacimiento y en el individuo adulto. Por lo demás y en el caso de éste último, esta plasticidad se pone de manifiesto característicamente en el patrón de recuperación de la capacidad lingüística tras un daño cerebral o en el proceso de aprendizaje de nuevas lenguas. Existe constancia, efectivamente, de la existencia en la etapa adulta de significativas remodelaciones (generalmente postraumáticas) de los centros del lenguaje (Thomas y otros 1997), consistentes fundamentalmente en una alteración del patrón de lateralización tan característico de la organización anatómica y funcional del lenguaje, marcado por la dominancia del hemisferio izquierdo (Thomas y otros 1997). Del mismo modo, el aprendizaje de una segunda lengua suele dar lugar a un reclutamiento de regiones corticales que no se utilizaban para el procesamiento de la L1, observándose además en este caso una mayor variabilidad individual al respecto (Dehaene y otros 1997). Este tipo de evidencias parece sugerir que la plasticidad neuronal es una propiedad inherente de los sistemas lingüísticos (y no un simple mecanismo compensatorio de hipotéticos daños que afecten a su integridad), confirmando el papel crucial de la experiencia a este respecto. Como cabría esperar, el grado de plasticidad de las estructuras cerebrales responsables del procesamiento lingüístico es sustancialmente mayor en el individuo en desarrollo en comparación con el existente en el individuo adulto. Así, muchas de las grandes restricciones que existen en este último caso, como la 
dominancia del hemisferio izquierdo o el carácter auxiliar de los lóbulos temporal y frontal derechos, no parecen ser características obligadas en el primero (Bates y otros 1997). De hecho, los niños que han sufrido lesiones significativas en las áreas corticales «clásicas» del lenguaje terminan recuperando con el tiempo una capacidad lingüística casi completa (Bates y otros 1992). No obstante, este hecho no implica que la plasticidad adaptativa del cerebro infantil sea ilimitada, dado que determinadas lesiones pueden tener un efecto permanente y provocar complejos trastornos en el estadio adulto (Deacon 2000, p. 273). Lo que sucede normalmente es que las lesiones tempranas suelen dar lugar a una reordenación más profunda de los centros cerebrales implicados en el procesamiento del lenguaje (incluyendo su transferencia al hemisferio derecho), la cual puede producirse, en todo caso, a costa de otras regiones, comprometiendo de esta manera otras funciones cerebrales (plasticidad maladaptativa). En cambio, las lesiones más tardías suelen provocar únicamente una reorganización cortical intrahemisférica, que permite recuperar funcionalmente áreas vecinas que estaban activas en una fase previa del desarrollo (Hernández-Muela y otros 2004). La recuperación tras las lesiones precoces se produce, en particular, merced al reclutamiento de regiones corticales muy diversas, incluyendo los córtices prefrontal, frontal inferior y parietal inferior, en el caso del lenguaje expresivo, así como temporal inferior, temporal frontal y temporal superior, si se trata del componente receptivo (Müller y otros 1999). En todo caso, y en consonancia con el modelo de emergencia de las habilidades cognitivas propuesto por Johnson (2003), según el cual las propiedades funcionales de las diferentes regiones cerebrales surgen, en gran medida, como consecuencia de su interacción y de su competencia con otras regiones por ocuparse de una determinada función, todas estas zonas estarían seguramente activas durante la ontogenia lingüística, si bien su implicación en el procesamiento del lenguaje se iría reduciendo conforme se fuera alcanzando en el individuo sano la competencia lingüística normal. La experiencia juega un papel decisivo en este fenómeno.

Es importante señalar, por último, que la significativa contribución de la experiencia a la organización estructural de los sistemas encargados del procesamiento lingüístico se debería, asimismo, a las propias características asociativas e integrativas de los circuitos neuronales, así como al hecho de que su diseño implique en muchos casos una asociación recurrente entre determinadas regiones lingüísticas y determinados centros de almacenamiento de información (Nobre y Plunkett 1997).

Por consiguiente, y teniendo en cuenta la importancia que reviste la experiencia en el proceso de adquisición del lenguaje, se han planteado numerosas objeciones a las tesis que defienden el carácter innato del lenguaje. Por un lado, dichas objeciones se centran fundamentalmente 
en el modo en que tiene lugar dicho proceso, que para diversos autores estaría insuficientemente estudiado (Pullum 1996), pero por otro, lo hacen en la naturaleza del input lingüístico del que depende y que lo condiciona, que es la cuestión de la que se ocupa preferentemente este artículo (v. apartado 4). Así, se ha sugerido, en particular, que un análisis empírico exhaustivo de los estímulos lingüísticos que recibe el niño durante su desarrollo permitiría cuestionar seriamente la supuesta «pobreza del estímulo» defendida por las tesis innatistas (Ritter 2002; Cameron-Faulkner y otros 2003; Newmeyer 2003). Asimismo, se ha indicado que, aun en el caso de que la «pobreza del estímulo» durante la ontogenia tuviera el alcance que se le supone, esta supuesta paradoja no justificaría necesariamente la existencia de una Gramática Universal autónoma codificada genéticamente, sino más bien la presencia de algún tipo de sistema cognitivo innato (cf. Newmeyer 1997). Del mismo modo, se ha aducido que el hecho de pretender que las reglas sintácticas deban estar determinadas genéticamente supone obviar las numerosas evidencias que parecen sugerir que el aprendizaje asociativo, la imitación y el contexto social desempeñan un papel fundamental en el proceso de corrección de los errores, el cual resultaría necesario a su vez para la adecuada adquisición de la sintaxis (y, por extensión, del lenguaje) (Lieberman 2002; pero v. apartado 4). En este sentido, numerosos autores sostienen que no sería lo mismo un lenguaje genéticamente codificado que una habilidad genéticamente codificada para aprenderlo, en el sentido de que los procesos que intervendrían en la adquisición del lenguaje serían los mismos que permiten la adquisición de otras habilidades cognitivas (Greenfield 1991; Bates y otros 1992; Elman y otros 1997).

Conviene precisar, finalmente, que, como quiera que la intención de este trabajo es la de centrarse preferentemente en la naturaleza del input lingüístico y en su papel durante el proceso de adquisición del lenguaje (v. apartado 4), se dejarán al margen tres tipos de evidencias fundamentales para quienes defienden una aproximación empirista a este fenómeno: (i) las evidencias de carácter funcionalista, que implican que el proceso de adquisición del lenguaje tendría por objeto el desarrollo de un sistema de actuación de carácter más pragmático, y no tanto la consecución de una competencia gramatical en los términos formulados por la teoría chomskyana (cf. Newmeyer 1997; Seidenberg y MacDonald 1999, p. 574), de modo que las propiedades de la gramática serían el resultado de una combinación de principios operativos generales del cerebro humano, en particular de los que regulan el procesamiento de información (Deane 1992); (ii) la aparente ausencia de una disociación completa entre los trastornos lingüísticos y los cognitivos (Newmeyer 1997); y (iii) la coheredabilidad y la comorbilidad que se observa en numerosas ocasiones entre dichos trastornos, como sucede, por ejemplo, en el caso de la dislexia y del trastorno por déficit de atención e hiper- 
actividad (Purvis y Tannock 1997), las cuales se deberían a la existencia de una base genética parcialmente común para los mismos, lo que, sin embargo, no significaría, en modo alguno, que el módulo del lenguaje no pueda (y deba) ser descrito como una entidad funcionalmente independiente resultante, en buena medida, de un programa genético específico (Benítez Burraco, 2007a).

\section{OBJEGIONES DE GARÁCTER INNATISTA A UNA APROXIMACIÓN EMPIRISTA AL PROGESO DE ADQUISICIÓN DEL LENGUAJE}

A pesar del relevante papel que desempeña la experiencia en el proceso, las evidencias discutidas en el apartado 2 cuestionan seriamente la idea de que la adquisición del lenguaje pueda caracterizarse como un «aprendizaje», esto es, como un incremento progresivo del inventario léxico y de los recursos sintácticos del niño como consecuencia de la gradual selección e incorporación de los elementos que integran el input lingüístico al que se ve expuesto. En este sentido, el argumento de la «pobreza del estímulo», y todas las implicaciones derivadas del mismo, se revelan como decisivos, por cuanto, como afirman Longa y Lorenzo 2008, dicho argumento no contribuiría tanto a validar el innatismo per $s e$, como a deslegitimar el empirismo y, en particular, la hipótesis de que la adquisición de la lengua materna sea exclusivamente el resultado de un proceso de aprendizaje estadístico (o aprendizaje dependiente de los datos), de la enseñanza (facilitada o no por diversos tipos de «correcciones» o por el recurso a un discurso simplificado) y/o de la mera la imitación.

a) Por qué la adquisición del lenguaje no consiste en un aprendizaje dependiente de los datos. En lo que concierne al aprendizaje estadístico, se ha sugerido que los niños dispondrían de mecanismos de aprendizaje inducibles por la experiencia, los cuales no sólo les permitirían, por ejemplo, segmentar correctamente las palabras, sino, asimismo, adquirir los restantes componentes del lenguaje, en particular, los de naturaleza sintáctica, de forma que no sería necesario postular la existencia de un conocimiento lingüístico innato para explicar el fenómeno de la adquisición del lenguaje (Saffran y otros 1996). Esta cuestión comporta, desde luego, cruciales implicaciones en lo que concierne a la organización de la cognición y al propio carácter innato del lenguaje (v. infra), pero baste indicar en este punto que diversas evidencias sugieren que, si bien es cierto que los niños disponen de una significativa capacidad computacional para detectar regularidades en la distribución de los elementos que integran el input, no parece probado, en cambio, que esta información permita por sí misma alcanzar ningún tipo de conocimiento lingüístico acerca de la estructura gramatical (Lust 2006, pp. 114-118). La razón fundamental para ello residiría en la propia natu- 
raleza del input lingüístico, tal como se caracterizó en el apartado precedente al discutir el argumento de la «pobreza del estímulo». Merece la pena recordar a este respecto el hecho de que el input es defectivo y que puede contener información engañosa (lo que incluye la propia posibilidad de que el niño lleve a cabo una interpretación incorrecta de enunciados perfectamente gramaticales emitidos por el adulto) (Fodor y Crowther 2002). La circunstancia de que el niño haya de soslayar este tipo de dificultades (y el hecho de que lo haga de forma recurrente y con particular eficacia) incrementa la complejidad potencial a la que debería enfrentarse un sistema de aprendizaje dependiente de los datos. Por el contrario, la existencia de algún tipo de conocimiento lingüístico innato minimizaría el daño que para la adecuada consecución de la adquisición del lenguaje supondría este tipo de datos lingüísticos no verídicos, facilitando, en consecuencia, el proceso de adquisición y (lo que resulta ciertamente relevante) determinando para qué tipos de fenómenos se haría necesaria una mayor exposición ambiental (Fodor y Crowther 1992). Otra cuestión importante a este respecto, y relacionada con la anterior, la constituye la ambigüedad inherente a determinados datos positivos que integran el input lingüístico (Fodor y Crowther 2002), como sucede, por ejemplo, con aquellas estructuras superficiales cuya ambigüedad no viene marcada explícitamente. Una estrategia de aprendizaje estadístico difícilmente lograría explicar el modo en que el niño es capaz de desentrañar este tipo de ambigüedad e interpretar correctamente dichas oraciones; en cambio, algo así resultaría posible si se acepta que el niño es consciente de algún modo de la existencia de una estructura jerárquica subyacente a la secuencia lineal de elementos que percibe (Crain y Pietroski 2002). Como se discute en el apartado 6, el proceso de adquisición del lenguaje se describe siempre con mayor exactitud si se asume que durante el mismo el niño va elaborando activamente posibles formas de usar la lengua a partir de lo que oye (incluyendo diversas hipótesis acerca de la estructura de los constituyentes), para probar seguidamente si la teoría gramatical que ha desarrollado se muestra correcta o equivocada.

b) El papel desempeñado por el «habla del cuidador». Es evidente que un aprendizaje estadístico se vería facilitado si el input que resulta necesario procesar se simplificara o se adaptara de algún modo a la (presumiblemente menor o insuficientemente desarrollada) capacidad de procesamiento (y aprendizaje) del niño, de ahí el interés que ha despertado tradicionalmente el análisis del «habla del cuidador»o «maternés». Este tipo de habla podría definirse como el estilo discursivo que adoptan quienes pasan mucho tiempo interactuando con niños pequeños. Aunque pueden existir algunas diferencias interculturales al respecto, parece tratarse de un fenómeno universal (Snow y Ferguson 1977). Este discurso se caracteriza, entre otros rasgos, por una entonación particularmente marcada, una mayor claridad fonológica, un volumen anor- 
malmente elevado al hablar, un tempo más lento al hacerlo, la presencia de formas asociadas al balbuceo y de palabras simplificadas, la utilización de oraciones más breves y con una estructura más simple, una distribución proporcional diferente de las construcciones sintácticas (de modo que, por ejemplo, las interrogativas, imperativas y deícticas se vuelven más frecuentes, mientras que las enunciativas se hacen más raras), una alteración de la frecuencia de determinadas transformaciones sintácticas y una frecuencia más elevada de repetición de muchos de los términos empleados (Newport y otros 1977; Lust 2006, pp. 110-114; v. tabla 1). Se ha sugerido, en particular, que las propiedades restrictivas que caracterizan a este tipo de discurso desempeñarían un papel causal en la adquisición del lenguaje (Newport y otros 1977).

\begin{tabular}{|c|c|c|c|}
\hline & $\begin{array}{l}\text { Discurso } \\
\text { dirigido al niño }\end{array}$ & $\begin{array}{c}\text { Discurso } \\
\text { entre adultos }\end{array}$ & $\begin{array}{l}\text { Texto } \\
\text { escrito }\end{array}$ \\
\hline LME (lingitud media del enuciado) (en palabras) & 4,24 & 11,94 & 19,57 \\
\hline Número medio de proposiciones por enunciado & 1,16 & 2,66 & 2,88 \\
\hline \multicolumn{4}{|l|}{ Con relación al total de enuciados, \% de los mismos: } \\
\hline que resultan fragmentarios o consisten en frases hechas & 36 & 28 & 0 \\
\hline que resultan imposibles de analizar & 4 & 9 & 0 \\
\hline que son agramaticales & 0 & 5 & 0 \\
\hline que son completamente gramaticales & 60 & 58 & 100 \\
\hline que tienen un carácter enunciativo & 38 & 87 & 100 \\
\hline que constituyen preguntas de tipo sí-no & 23 & 8 & 0 \\
\hline que constituyen preguntas con partícula $\mathrm{cu}$ - & 21 & 1 & 0 \\
\hline que tienen un carácter imperativo & 18 & 2 & 0 \\
\hline $\begin{array}{l}\text { en los que no se han producido desplazamientos de elementos (pro- } \\
\text { posiciones intactas) }\end{array}$ & 28 & 45 & \\
\hline $\begin{array}{l}\text { en los que se han producido movimientos menores ( se han desplaza- } \\
\text { do, por ejemplo, las partículas) }\end{array}$ & 7 & 10 & s.d. \\
\hline en los que se ha producido una inversión de Aux & 14 & 6 & s.d. \\
\hline $\begin{array}{l}\text { que se pueden considerar formas } \mathrm{cu} \text { - o en los que se ha producido un } \\
\text { movimiento } \mathrm{Cu}^{-}\end{array}$ & 16 & 10 & s.d. \\
\hline en los que ha tenido lugar una deleción & 33 & 26 & s.d. \\
\hline $\begin{array}{l}\text { en los que se han producido deformaciones complejas (como, sucede, } \\
\text { por ejemplo, en las construcciones pasivas) }\end{array}$ & 0 & 4 & s.d. \\
\hline
\end{tabular}

Tabla. Análisis comparativo de las características más significativas del discurso hablado dirigido al niño, de la interacción hablada entre adultos y de los textos escritos. En los dos primeros casos los resultados se han tomado de Newport (1977). Los datos concernientes al discurso hablado dirigido al niño proceden, en particular, del examen de cien enunciados distintos dirigidos a sus hijos por cada una de las madres que integraban el grupo experimental (constituido por un total de quince sujetos), mientras que los correspondientes a la interacción discursiva entre adultos provienen del análisis de los cincuenta enunciados que cada una de las madres participantes en el ensayo dirigieron al investigador en las mismas condiciones experimentales. Por su parte, los datos relativos al texto escrito se han tomado de Fodor y Crowther (2002), y derivan del análisis de un fragmento de alrededor de 180 palabras procedente de The Wall Street Journal (número del 27 de febrero de 2001, columna 1 de la página A1, comenzando en la primera palabra de la misma). Abreviaturas: s.d., sin determinar. 
El argumento de la «pobreza del estímulo» también resulta plenamente válido en este caso, por cuanto las propias características del «maternés» hacen que el niño se vea expuesto a una densidad anormalmente reducida (o subóptima) de evidencias concernientes a fenómenos sintácticos claves que, sin embargo, termina dominando en la etapa adulta. Sería el caso, por ejemplo, de los movimientos de partículas $\mathrm{cu}$ - a larga distancia o de la complementización de adverbios subordinantes (Fodor y Crowther 2002).

c) La cuestión de las correcciones. Por otro lado, también resulta poco probable que las «correcciones» que los adultos hacen al niño cuando habla condicionen sustancialmente la manera en que éste lo hace. En este caso, la hipótesis empirista de partida consistiría en que la adquisición del lenguaje se explicaría, en gran medida, por la capacidad que presentarían los niños de determinar el grado de incorrección de sus propios enunciados atendiendo para ello a las construcciones alternativas (o reformulaciones; en inglés, recasts) generadas por sus interlocutores adultos (cf. la revisión que Moerk (1991) hace de la importancia de este componente del input lingüístico). Las evidencias negativas formuladas por los adultos también podrían revestir un carácter indirecto o implícito, en forma de (a) repeticiones de enunciados incorrectos generados por el niño, con objeto de dirigir su atención hacia los mismos; (b) petición de aclaraciones al niño acerca de lo dicho (Demetras y otros 1986; Bohannon y Stanowicz 1988); o (c) el mero hecho de no emplear las construcciones incorrectas que el niño genera (Lust 2006, pp. 3031). Sin embargo, el análisis pormenorizado de las interacciones discursivas entre padres e hijos ha puesto de manifiesto que ni la naturaleza ni la frecuencia de las correcciones directas poseen la entidad que se les ha venido presuponiendo, por cuanto (a) habitualmente se dejan sin corregir la mayoría de las oraciones incorrectas que formulan los niños (Hirsh-Pasek y otros 1984); (b) el número de oraciones agramaticales emitidas por éstos es demasiado bajo como para poder elicitar el proceso de corrección que sería necesario para lograr eliminar eficazmente la totalidad de las generalizaciones incorrectas que el niño hubiera podido realizar (Fodor y Crowther 2002); (c) los padres repiten y modifican parcialmente enunciados perfectamente correctos generados por sus hijos (Hirsh-Pasek y otros 1984); (d) la diferencia entre la frecuencia de corrección de las oraciones correctas y las incorrectas sólo resulta estadísticamente significativa en determinados casos (Hirsh-Pasek y otros 1984); (e) con relativa frecuencia, los padres repiten enunciados imperfectos emitidos por sus hijos sin manifestar una desaprobación aparente (Post 1994); (f) los padres atienden preferentemente en sus correcciones al significado de las oraciones generadas por sus hijos, de modo que pueden aceptar como correctas construcciones que contienen errores 
fonológicos o sintácticos (Brown y Hanlon 1970); (g) la frecuencia de las reformulaciones es muy reducida en el caso de otros individuos con los que interactúa habitualmente el niño, como los hermanos mayores (Strapp 1999); (h) no todos los padres se muestran igualmente proclives a la hora de proporcionar las reformulaciones (Newport y otros 1977); y (i) existen significativas diferencias interculturales en lo concerniente a la frecuencia de uso y a la naturaleza de este tipo de correcciones (Lieven 1994).

En consecuencia, no parece haber una correlación significativa entre la tasa de éxito en la adquisición del lenguaje y la frecuencia o el tipo de correcciones a las que se ve expuesto el niño. Por otra parte, existen diversas evidencias que sugieren que las reformulaciones no siempre tendrían el efecto discernible, evidente o automático que se les presupone (Marcus 1993; Morgan y otros 1995), de modo que sólo parecen resultar efectivas si (a) suponen un contraste directo e inmediato entre la forma en que el propio niño dice las cosas y la manera en que lo hace el adulto (Saxton 1997; Saxton y otros 1998); y (b) el niño ya es capaz en gran medida de usar por sí mismo la forma correcta en cuestión (Saxton 1998). En conjunto, todas estas evidencias parecen indicar que, al margen de lo que sucede en el caso concreto del aprendizaje de los elementos léxicos individuales, la utilidad de las correcciones en lo concerniente al proceso de adquisición del lenguaje (y especialmente del componente sintáctico) consistiría fundamentalmente en que permitirían recordar y afianzar el uso de determinadas formas aprendidas previamente, y no tanto en aprender formas nuevas. La presencia de evidencias negativas insuficientes y asistemáticas (o su inexistencia, para determinados autores) en el input que recibe el niño, y a la que se aludió sucintamente al tratar el argumento de la "pobreza del estímulo", ocupa, para Fodor y Crowther (2002), una posición central en la hipótesis del innatismo lingüístico, por cuanto un dispositivo de aprendizaje dependiente de los datos se vería incapaz de deducir a partir de un input con estas características las restricciones que están siempre presentes en cualquier gramática (filtros, enunciados de obligatoriedad, limitaciones contextuales al uso de las reglas, etc.).

d) Por qué el aprendizaje del lenguaje no consiste en imitar. La razón fundamental por la que las estructuras sintácticas que emplean los niños pequeños no se adquieren mediante un proceso de «imitación» estriba en que la capacidad de imitación de los niños no resulta, de hecho, demasiado notable, de modo que éstos suelen limitarse a repetir aquellas estructuras que han adquirido previamente, como se pone de manifiesto habitualmente en los tests de imitación destinados a evaluar el nivel de desarrollo lingüístico del niño (Lust y otros 1996). El análisis de los corpus de habla infantil indica, asimismo, que las repeticiones exactas de los enunciados emitidos por los adultos (en el sentido de presentar las 
mismas palabras con contenido léxico y dispuestas en el mismo orden) son poco frecuentes, existiendo, además, una significativa variabilidad individual a este respecto. Este tipo de análisis también ha confirmado la idea de que las estructuras imitadas ya estaban presentes en el habla espontánea del niño (Bloom y otros 1974). Por lo demás, parece probado que la imitación no constituye casi nunca una mera copia pasiva de lo escuchado, sino que implica casi siempre un análisis y una reconstrucción del input (Lust 2006, pp. 120, 134-135). Este hecho ha llevado a sugerir, en una formulación menos restrictiva, que los niños podrían adquirir el lenguaje mediante un proceso de generalización. Ciertamente los niños generalizan, pero no lo hacen de forma indiscriminada (Fodor y Crowther 2002). Además, cuando los niños proyectan nuevas oraciones sobre la base de otras que han escuchado previamente, no se limitan a colocar nuevos elementos léxicos en los huecos (slots) existentes en la estructura de la oración oída, sino que son capaces, si es necesario, de expandir dicha estructura, con objeto de incluir nuevas cláusulas, o de reemplazar determinados componentes por otros jerárquicamente equivalentes (Fodor y Crowther 2002). En suma, si bien resulta evidente que determinados elementos se aprenden por imitación, como sucede paradigmáticamente con las palabras, este proceso no desempeñaría un papel causal relevante en la adquisición de la sintaxis (Lust 2006, p. $120)$.

\section{LA OPTIMIZACIÓN DE LA HIPÓTESIS INNATISTA: PRINCIPALES DIREC- TRICES}

a) La consideración de los datos biológicos. Teniendo en cuenta lo discutido hasta el momento, parece razonable recurrir a otro tipo de evidencias, al margen de las estrictamente lingüísticas, para tratar de dilucidar si el lenguaje humano tiene un carácter innato. Newmeyer (1997) sugiere que son tres las razones fundamentales por las que hasta la fecha no se han incluido en la discusión acerca de esta cuestión datos empíricos de índole extralingüística, fundamentalmente evidencias clínicas y conductuales que demostrasen la existencia de una disociación entre una supuesta gramática autónoma e innata y otras capacidades cognitivas involucradas en el lenguaje y necesarias para su adquisición. Una primera causa respondería, según este autor, a la preferencia de los propios lingüistas por la utilización de datos empíricos de carácter gramatical, fácilmente obtenibles, en contraposición con las dificultades que plantean el diseño y la realización de análisis clínicos y genéticos, sobre todo a la hora de definir y delimitar la composición de las muestras que deben someterse a este tipo de análisis. En segundo lugar se encontraría el hecho de que en la inmensa mayoría de los casos clíni- 
cos documentados hasta la fecha en los que se observa una disfunción de la competencia lingüística, dicha disfunción compromete aspectos demasiado generales del lenguaje y no parece afectar de forma exclusiva a ninguna de las entidades gramaticales definidas por los diferentes modelos teóricos desarrollados desde el campo de la Lingüística. Una tercera y última razón sería la más que probable inviabilidad metodológica del análisis experimental de la competencia lingüística a través del estudio de la actuación, debido seguramente a que en el paso de la una a la otra se encuentran implicados diversos sistemas cognitivos (algunos probablemente aún por descubrir y caracterizar), lo que oscurecería indefectiblemente el análisis de la primera si únicamente se empleara la batería de experimentos psicolingüísticos utilizados habitualmente en el estudio de la segunda.

b) La idea del genotipo lingüistico. En todo caso, en atención a la tesis fundamental del innatismo, y tomando prestado el concepto del ámbito de la Genética, Anderson y Lightfoot 2000 han sugerido la existencia de un genotipo lingüístico, que consistiría en toda aquella información que no derivaría de la experiencia y que resultaría imprescindible para la construcción de la Gramática Universal (en el sentido definido por Chomsky y al que se aludió al comienzo del apartado 2). Dos serían las características fundamentales de esta Gramática, a saber, su capacidad para generar un conjunto infinito de oraciones, al operar computacionalmente, y el hecho de que estaría formada por un número finito de elementos que poseerían propiedades distintivas; por otro lado, su organización sería modular, de forma que un inventario mínimo de dichos componentes incluiría, según Anderson y Lightfoot (2000), un lexicón, un juego limitado de estructuras organizativas de los elementos que lo componen y un dispositivo de intercambio de dichos elementos dentro de aquellas estructuras. Con respecto a la cuestión de los módulos que integrarían la facultad del lenguaje (y al propio módulo lingüístico en sí), lo cierto es que podrían estar contiguos o distantes en el tejido neuronal, de manera que resultaría plausible tanto una modularidad estructural (menos probable), como funcional (más probable). Por consiguiente, y en los términos genéticos más simples, el problema de la caracterización de la naturaleza innata del lenguaje ha buscado tradicionalmente hacer equivalentes (a) la capacidad para la adquisición y el uso del lenguaje (en esencia, la Gramática Universal) y el genotipo lingüístico, y (b) la gramática particular finalmente desarrollada por el individuo y el fenotipo lingüístico (v. figura 1), en la línea de lo postulado por el propio Chomsky al indicar, por ejemplo, que «el argumento de la pobreza del estímulo no nos deja más alternativa razonable que suponer que estas propiedades [las que caracterizan a la Gramática Universal] son determinadas de alguna manera en la Gramática Universal como parte del genotipo» (Chomsky 1980, pp. 75-76). 
Desde el punto de vista anatomofisiológico, la potencialidad (limitada) que implica el genotipo lingüístico se explicaría por la existencia de un estado inicial de desarrollo, coincidente con el momento del nacimiento, en el que existiría una sobreabundancia de conexiones sinápticas, la cual se iría reduciendo conforme los estímulos externos (esto es, la experiencia) fueran afectando diferencialmente a determinadas neuronas, específicamente adaptadas a reaccionar ante ellos, favoreciendo, consecuentemente, determinadas conexiones sinápticas en detrimento de otras, que permanecerían inactivas y que podrían terminar degenerando, de forma semejante a lo que ocurre con las neuronas del córtex visual (Hubel y Wiesel 1962), donde la organización de las columnas de dominancia ocular responde tanto a la información contenida en el genoma de las células relacionadas con la visión, como a la información procedente de otras regiones del cerebro y al patrón lumínico al que se expone la retina durante una fase concreta de su desarrollo (Deacon 2000).

La implicación directa del carácter innato del lenguaje (y de sus componentes) sería, en esencia, que la información (fundamentalmente genética) transmitida de padres a hijos determinaría en buena medida dicha capacidad lingüística, de forma que, independientemente de la dificultad técnica que pudiese plantear (v. figura 1), debería ser posible identificar física y funcionalmente los mecanismos genéticos responsables de la misma, como se viene haciendo con otras funciones cognitivas (Winterer y Goldman 2003).

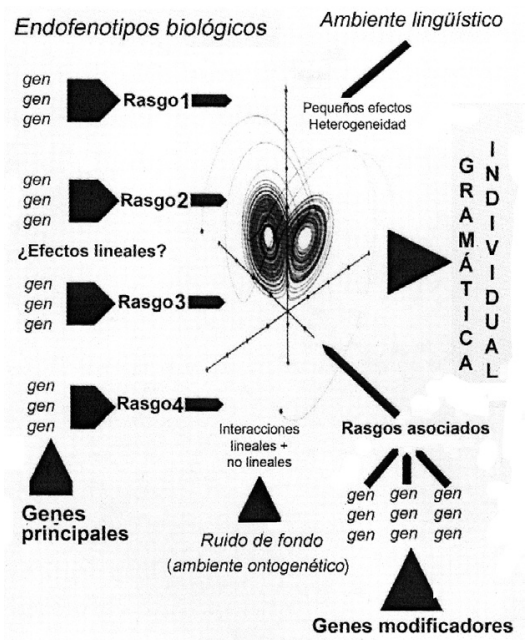

Figura. Esquema que ilustra la complejidad que presenta la dilucidación y el análisis del lenguaje en términos de genética molecular. Los genes principales responsables del mismo interactúan presumiblemente con genes moduladores, con el ruido molecular del organismo, de carácter aleatorio, y con multitud de factores ambientales, de forma que pueden 
originarse diversos endofenotipos biológicos, esto es, componentes cuantificables situados en el espacio comprendido entre la gramática individual y los propios genes, los cuales pueden revestir un carácter cognitivo, neuroanatómico, neurofisiológico, endocrino o bioquímico (Gould y Gottesman 2006) y, en último término, diferentes fenotipos cognitivos que pueden diferenciarse unos de otros en determinados aspectos. (Reproducido a partir de Brain research. Brain research reviews, vol. 43, G. Winterer y D. Goldman, «Genetics of human prefrontal function», pp. 134-163, (02003, con el permiso de la editorial Elsevier).

Como consecuencia de todo lo discutido en este apartado, Pinker 2001, pp. 350-352 propone que existirían centros del lenguaje que en el momento del nacimiento se caracterizarían por el hecho de que todas las conexiones posibles entre las neuronas que los constituyen estarían potencialmente disponibles (de ahí la capacidad de aprendizaje de cualquier lengua de la que disponemos durante los primeros años de nuestra vida), si bien durante la adquisición de la lengua predominante en el ambiente en que crece el individuo ciertas sinapsis se reforzarían en detrimento de otras. Necesariamente también, Pinker considera que se haría preciso postular la existencia de «genes del lenguaje». La definición que de ellos propone este investigador sería la de «secuencias de ADN que codifican proteínas o desencadenan la trascripción de otras proteínas, en determinados momentos y lugares del cerebro, que guían, fijan o atraen neuronas hacia aquellos circuitos que, una vez producido el ajuste sináptico que tiene lugar con el aprendizaje, intervienen en la solución de problemas gramaticales» (Pinker 2001, pp. 352-353); las características estructurales y funcionales más significativas de los «genes del lenguaje» caracterizados hasta el momento se han discutido en otro lugar (Benítez-Burraco 2004, 2006).

c) La redefinición del concepto «innato». Llegados a este punto, conviene dejar constancia, asimismo, del hecho de que el término «innato» resulta, ciertamente, particularmente elusivo y poco preciso desde un punto de vista biológico, y ello, cuando menos, por las siguientes razones: (a) porque su consideración implica la necesidad de tomar en cuenta mecanismos hereditarios alternativos a la codificación genética stricto sensu, como la epigénesis o la herencia materna; (b) porque se desconoce hasta qué punto la información no ambiental que determina las características y las propiedades de la facultad del lenguaje no se genera también como consecuencia del propio proceso de desarrollo; (c) porque su consideración debería llevar, asimismo, a una reevaluación crítica de fenómenos como el aprendizaje social y la cultura, que también pueden considerarse como una forma de herencia relevante en el caso de ciertos fenotipos conductuales (y, desde luego, en el del lenguaje) (Avital y Jablonka 2000; Jablonka y Lamb 2005); y (d) porque el término «innato» puede aludir a formas sustancialmente diferentes de regulación del desarrollo y la organización de las estructuras cerebrales, como las que 
implican, por una parte, el Sistema Funcional del Lenguaje (Lieberman 2000, 2002; v. infra) o la hipótesis de la Facultad del Lenguaje en sentido Amplio (Hauser y otros 2002), o, por otra, el modularismo (Fodor 1983), aunque con relación a este último caso, existirían también significativas diferencias entre un cerebro "prefijado» (en inglés, pre-wired) y uno «ensamblado» (en inglés, hard-wired) (Ramus 2006).

d) La consideración de nuevos marcos teóricos: el Programa Minimalista chomskyano. Conviene tener en cuenta, asimismo, que la naturaleza y el peso específico de lo innato en el propio pensamiento chomskyano han variado sustancialmente desde la década de los años noventa del pasado siglo, en concreto, tras el desarrollo del denominado Programa Minimalista (Chomsky 1995; Chomsky 2000). Según esta nueva hipótesis, el lenguaje sería un mecanismo de enlace (una interfaz) entre los sistemas cognitivos responsables del pensamiento y los encargados de la percepción y la motricidad (y, en particular, de la emisión y la recepción de gestos orales o manuales), y estaría constituido por dos componentes fundamentales: un lexicón y un sistema computacional, el cual, operando de forma recursiva, transformaría los elementos que integran el primero en palabras, sintagmas y oraciones. La naturaleza gramatical de este sistema computacional se habría reducido al máximo (idealmente habría desaparecido) y funcionaría según principios extremadamente simples (proyección asimétrica, merge binario, movimientos mínimos, etc.) (Longa y Lorenzo 2008). Por consiguiente, esta concepción de la facultad del lenguaje se aleja significativamente de la primitiva visión chomskyana del mismo en tanto que un sistema de conocimiento basado en principios composicionales altamente específicos y faltos de correspondencia con los que rigen otros dominios cognitivos (Lorenzo 2006, pp. 96, 97-98), de ahí que implique también una sustancial reducción de la cantidad de información «específicamente lingüística» de carácter «innato» necesaria para el desarrollo de una capacidad lingüística plena (Lorenzo y Longa 2003); las razones para ello se discuten de forma más detallada en el apartado siguiente.

e) La redefinición del concepto «modulable por la experiencia». Resulta preciso, por último, discutir críticamente el concepto de la «plasticidad», que desempeña, en relación con la «experiencia», un importante papel en todo lo argumentado en este artículo. Como se discutió en el apartado 3, la arquitectura precisa de las estructuras neuronales depende en último término del ambiente, lo que hace que la organización definitiva y la implicación exacta de las distintas regiones neuronales en el procesamiento lingüístico difieran en cierta medida de un hablante a otro de una misma lengua, dado que la experiencia (lingüística) acumulada a lo largo de sus vidas no es nunca la misma (Damasio y otros 1996). Por consiguiente, la base neuronal del lenguaje debe ser ligeramente diferente en cada uno de ellos desde un punto de vista anatómico y funcional, del mismo modo que tampoco serán nunca exactamente idénticas 
las gramáticas mentales empleadas por dichos individuos (Anderson y Lightfoot 2000). Sin embargo, y a pesar de su significativa importancia, conviene tener presente que la plasticidad es uno de los procesos neuronales sometidos a un control genético más preciso, de forma que no debería confundirse, sin más, con «aprendizaje» o «modulable por la experiencia en sentido laxo», puesto que en modo alguno implica la posibilidad de una completa remodelación de una determinada estructura neuronal por efecto de un cambio en las condiciones ambientales, sea cual sea la naturaleza del mismo (Ramus 2006). Esta precisión resulta especialmente válida en lo que concierne al lenguaje, que es en todos los casos una entidad cognitiva describible y caracterizable en el estadio adulto, la cual, como se ha discutido al comienzo de este apartado, surge siempre de forma recurrente a lo largo de la ontogenia merced, en buena medida, a un programa de desarrollo innato.

\section{El PROCESO DE ADQUisición DEL LENGUAJE}

Teniendo en cuenta todo lo discutido hasta el momento, parece evidente que una visión mucho más realista del proceso supone considerar que la adquisición del lenguaje no depende de forma exclusiva de las características del input lingüístico, en el sentido de que no se agota (ni consiste exactamente) en la extracción de la información de índole lingüística que contiene dicho input, sino que precisa, por el contrario, de la creación previa por parte del niño de una teoría acerca de la lengua a la que está expuesto y de una ulterior comprobación del grado en que dicha teoría se ajusta al input percibido. En este sentido, los niños «son selectivos y reconstructivos» en su utilización de los datos lingüísticos primarios, puesto que los emplean constantemente para reajustar y optimizar la arquitectura de la teoría que crean acerca de su propia lengua (Lust 2006, p. 121). O dicho de otro modo: la adquisición de la gramática no se produce por inferencia a partir de una masa crítica de oraciones aprendidas, sino que el niño va reformulando constantemente una hipótesis sobre la misma conforme interactúa con el ambiente lingüístico que lo rodea (Fodor y Crowther 2002).

Ahora bien, y como apuntan Longa y Lorenzo 2008, para la teoría actualmente dominante acerca de la adquisición del lenguaje el proceso caracterizado anteriormente difícilmente puede tener lugar en ausencia de algún tipo de conocimiento gramatical innato o, siendo quizás más precisos, de un dispositivo de adquisición del lenguaje. Como se apuntó en el apartado 2 al discutir las implicaciones del argumento de la "pobreza del estímulo», la existencia de determinadas restricciones de carácter innato acerca de las características que pueden adoptar las posibles gramáticas que se van generando durante el proceso de adqui- 
sición parecería ser una condición previa para poder emplear de forma productiva los datos que proporciona el propio input lingüístico (Fodor y Crowther 2002). Entre dichas restricciones se han mencionado, por ejemplo, la Restricción del Valor Único o la Restricción de la Avidez (Gibson y Wexler 1994). En todo caso, el papel que desempeñaría la Gramática Universal en este proceso sería el de restringir el número (en la práctica, infinito) de gramáticas potencialmente construibles a partir del input (o acaso, el de priorizar algunas de ellas sobre las restantes), de modo que fuera factible comprobar on-line su idoneidad con respecto a dicho input y, consecuentemente, extraer tanta información como fuera posible a partir de las oraciones que se vayan escuchando (Fodor y Crowther 2002). Por otro lado, la Gramática Universal contendría aquellas restricciones que resultan imposibles de deducir de un input que carece de evidencias negativas en el sentido discutido en el apartado 4. En su formulación más extrema, esta hipótesis sugeriría que la Gramática Universal definiría las posibles estructuras sintagmáticas, ligamientos, cadenas, categorías nulas, estructuras argumentales y rasgos sintácticos que pueden presentar las oraciones (Fodor y Crowther 2002).

En esta línea, y en atención al papel relevante que, como se propuso en el apartado anterior, esperamos de la Biología en la caracterización de la facultad del lenguaje y de su proceso de adquisición, podríamos afirmar que el genotipo lingüístico proporcionaría una serie de elementos invariantes (principios) de la gramática, pero, asimismo, otros elementos que admitirían diversas posibilidades (parámetros), de manera que los valores que tomarían finalmente dichos parámetros dependerían del ambiente lingüístico que rodeara al individuo durante su desarrollo (Anderson y Lightfoot 2000), de ahí que la arquitectura definitiva del sistema lingüístico (y, por extensión, de cualquier sistema cognitivo) que surgiera de este proceso de maduración sería necesariamente el resultado del aprendizaje y se hallaría indefectiblemente condicionada por la experiencia a la que se viera expuesto el individuo (Piattelli-Palmarini 1989). La importancia que reviste el hecho de que, como afirmaba Lust (2006, p. 121), el niño no adquiera el lenguaje en virtud exclusivamente de un proceso de aprendizaje dependiente de los datos, sino que imponga una determinada estructura (esto es, una teoría de la gramática) al input al que se ve expuesto, no implicaría, sin embargo, que, como también se ha comentado de forma sucinta en este trabajo, determinados mecanismos de aprendizaje no desempeñaran un papel relevante en la adquisición del lenguaje (Fodor 2001). Sería el caso, en particular, de ciertos principios inductivos generales, como (i) el Principio de Inclusión, que impone la solución menos restrictiva cuando son posibles más de una en virtud de las características del input; (ii) el Principio de Unicidad, según el cual existiría una única forma correcta de expresar una determinada proposición; o (iii) el Principio Conser- 
vativo, que impele a realizar generalizaciones de pequeño alcance y a no sobregeneralizar (Berwick 1985), así como (iv) el Principio del Contraste, según el cual dos formas cualesquiera han de diferenciarse en su significado (Clark 1987). En términos de la formulación maximalista a la que se aludía anteriormente, la teoría ortodoxa de la adquisición del lenguaje sostiene que la gramática individual (o fenotipo lingüístico), en tanto que entidad psicológica que expresa el desarrollo pleno de la capacidad lingüística de cada individuo (Anderson y Lightfoot 2000), resulta, como cualquier otro carácter biológico, de la interacción del genotipo lingüístico (o Gramática Universal) con el ambiente, es decir, con los datos lingüísticos primarios (v. figura 1), de forma que la experiencia elicitaría un número restringido de respuestas, en particular, aquellas preestablecidas genéticamente, si bien sería incapaz de determinar la forma básica de dicha respuesta. Esto supondría que la Gramática Universal sería un estado inicial; la gramática adquirida, un estado final; y que existiría un número determinado y finito de rutas preestablecidas que llevarían de las propiedades de una a las de la otra. La ruta elegida dependería de las circunstancias ambientales experimentadas por el sujeto a lo largo de su crecimiento, de ahí que resulta siempre más apropiado hablar de «desarrollo o adquisición del lenguaje» que de «aprendizaje» para describir este itinerario de maduración regulado (Anderson y Lightfoot 2000).

Como no podía ser de otro modo, el Programa Minimalista reconoce necesariamente la importancia que para el desarrollo del lenguaje, en general, y de cada lengua concreta, en particular, tienen ambos factores, que se han venido a conocer, respectivamente, como estado inicial $\left(\mathrm{S}_{0}\right)$ de la facultad del lenguaje (FL) (que equivaldría al genotipo lingüístico) y como datos lingüísticos primarios. No obstante, Chomsky 2001, pp. 1-2 ha sugerido que existiría, asimismo, un tercer factor implicado en el proceso, que habría que entender como un conjunto de leyes que rigen la autoorganización de los sistemas orgánicos y entre las que podrían citarse determinados principios de análisis de datos (de especial relevancia durante el proceso de adquisición del lenguaje, como ya se ha comentado) y principios de arquitectura estructural, así como determinadas restricciones al desarrollo, incluyendo principios de computación eficiente (Chomsky 2005, p. 6). La relevancia que dentro del Programa Minimalista cobra este «tercer factor» no excluye, sin embargo, el hecho de que para Chomsky ciertos aspectos de la facultad del lenguaje se seguirían derivando de principios específicos de dominio (esto es, de la Gramática Universal, del «estado inicial» o del «primer factor», como se prefiera), lo que diferenciaría esta nueva propuesta chomskyana de las tesis que defienden la existencia de un «innatismo general» (cf. O’Grady 2003) y a las que, como se apuntó al comienzo de este artículo, se aproxima, ciertamente, el Programa Minimalista. 
No cabe duda de que un análisis del proceso de adquisición del lenguaje desde los presupuestos del Programa Minimalista tendría un marcado interés para una caracterización del lenguaje como la que se pretende en este trabajo, en particular, por sus implicaciones en lo concerniente a la naturaleza y el alcance del innatismo lingüístico, así como acerca de la ontogenia y la filogenia del «órgano del lenguaje». Sin embargo, y tal como apuntan Longa y Lorenzo acertadamente (2008), la teoría de la adquisición del lenguaje dominante actualmente sigue anclada en los presupuestos más ortodoxos de una aproximación maximalista a dicho proceso (rindiendo descripciones de la ontogenia lingüística como la propuesta por Anderson y Lightfoot 2000), la cual, al contrario que la que propugna el minimalismo chomskyano (i) quiere ver en el lenguaje una facultad cognitiva independiente, que sería en gran medida el resultado de un dispositivo gramatical autónomo que impondría una forma (gramatical) al pensamiento con objeto de poder transmitirlo; (ii) concibe la Gramática Universal como una suerte de estado inicial $\left(\mathrm{S}_{0}\right)$ altamente articulado, cuyos principios serían específicos de dominio, que tendría un carácter doblemente modular (lo sería la propia facultad del lenguaje en relación con la cognición y, a su vez, los distintos subsistemas que componen la primera) y con una arquitectura organizada en múltiples niveles de representación (Longa y Lorenzo 2008); y (iii) en virtud de una consideración preferente del argumento de la «pobreza del estímulo» y de las implicaciones que de él se derivan, defiende un modelo de adquisición del lenguaje que Longa y Lorenzo 2008 han denominado el «modelo input-output» del innatismo lingüístico, desde el momento en que sería el desajuste observado entre la «pobreza» del input lingüístico al que el niño se ve expuesto durante el proceso de adquisición y la «riqueza» del output resultante del mismo el que sugeriría que durante dicho proceso se recurre a información gramatical relevante no derivable de la experiencia (y, por consiguiente, innata).

Por el contrario, el minimalismo (i) defiende la inespecificidad de los principios que constituyen la facultad del lenguaje; (ii) abandona la idea de la modularidad interna de la misma (y relativiza, al mismo tiempo, el carácter modular de la facultad en sí), reduciendo dicha facultad a una distinción mínima entre el lexicón y un sistema computacional (Longa y Lorenzo 2008); y (iii) propugna un modelo de adquisición del lenguaje que se ha caracterizado como «disposicional» (Longa y Lorenzo 2008), en el sentido de que la facultad del lenguaje sería meramente el resultado obligado de la interacción de los sistemas externos durante el desarrollo, siempre y cuando dicha interacción tuviera lugar en presencia de una cantidad umbral de estímulos lingüísticos. De forma más detallada, y en relación con las cuestiones tratadas específicamente en este artículo, cabría afirmar que las razones por las que esta nueva propuesta innatista permitiría analizar de forma más precisa y productiva el 
proceso de adquisición del lenguaje serían las siguientes:

a) Implicaría una formulación del genotipo lingüístico más ajustada a la naturaleza y al alcance reales del mismo, por cuanto el estado inicial $\left(\mathrm{S}_{0}\right)$ pasaría a considerarse fundamentalmente una consecuencia del desarrollo y de la interacción entre sí de los sistemas externos, a los cuales quedaría subordinada funcionalmente la facultad del lenguaje. Este hecho supondría, por otra parte, una significativa reducción de la información genética necesaria para el desarrollo de dicha facultad (Lorenzo y Longa 2003), por cuanto (a) gran parte de los genes que integrarían el genotipo lingüístico, en tanto que responsables también del desarrollo de los sistemas externos, no tendrían por qué poseer un carácter exclusivamente lingüístico; (b) el desarrollo y el funcionamiento del «órgano del lenguaje» dependerían, hasta cierto punto, de leyes generales de organización de los sistemas biológicos, que son independientes del ambiente y del genoma; y (c) una parte de la información necesaria para el desarrollo de dicho "órgano» tendría un carácter epigenético, derivando del ambiente en que tiene lugar la ontogenia.

b) Implicaría, por consiguiente, una formulación del concepto «innato» más ajustada a la naturaleza y al alcance reales del mismo (esto es, a su significado biológico), por cuanto el carácter innato del lenguaje descansaría ahora fundamentalmente en lo fenotípico, al considerarse como innata toda propiedad del sistema que apareciera de forma recurrente en un momento dado del desarrollo. Este hecho permitiría, en particular, dar cabida dentro del innatismo lingüístico a fenómenos como la epigénesis o el contexto ontogenético, cuya importancia desde el punto de vista biológico se discutió en el apartado anterior. En conjunto, y en un plano lingüístico, esta reformulación y la discutida en el punto anterior permitirían considerar como innatas determinadas propiedades de la gramática sin necesidad de que fueran la consecuencia de una instrucción codificada genéticamente, es decir, de un conocimiento lingüístico disponible en el momento del nacimiento. Así, por ejemplo, la organización jerárquica de los enunciados lingüísticos, que constituye un componente fundamental de la Gramática Universal, podría tratarse realmente de una propiedad obligada de cualquier sistema de naturaleza combinatoria (Berwick 1998) o ser el resultado de alguna propiedad característica de los sistemas externos, bien de la composicionalidad inherente al pensamiento (Cormack y Smith 2002), bien de la secuencialidad intrínseca a la planificación y a la ejecución de los movimientos motores (Calvin y Bickerton 2000).

c) Haría posible caracterizar de modo más exacto y más acorde con los datos biológicos el modo en que se produce la ontogenia del «órgano del lenguaje», por cuanto permitiría (a) tomar en consideración capacidades cognitivas que no son específicamente lingüísticas, lo que casaría con el modo en que parece funcionar el cerebro, en el sentido de que las diferentes estructuras neuroanatómicas que lo constituyen 
no parecen regular aspectos discretos del comportamiento, sino más bien determinados procesos básicos, de modo que un comportamiento complejo dependería, ante todo, de la forma en que se agrupan funcionalmente un amplio conjunto de circuitos neuronales (Lieberman 2002; v. también Benítez-Burraco 2005); (b) aceptar aquellos modelos de procesamiento lingüístico para los que las propiedades fundamentales del lenguaje serían una consecuencia de la actuación de componentes funcionales que también intervendrían en tareas cognitivas no lingüísticas, como sucede paradigmáticamente con el propuesto por Lieberman (2002), según el cual el lenguaje sería el resultado de un complejo y específico patrón de interconexión entre diferentes circuitos neuronales localizados en distintas regiones cerebrales, los cuales se encontrarían en la base de tres componentes funcionales diferentes: un dispositivo que permitiría procesar secuencialmente elementos de diversa naturaleza, un mecanismo de memoria encargado de mantener presentes dichos elementos mientras fueran procesados, y un dispositivo de almacenamiento de información lingüística y extralingüística sobre los elementos que habrían de procesarse; y (c) abandonar la idea de una gramática innata particularmente sofisticada (centrada, además, en lo sintáctico) y altamente compartimentalizada, lo que se adecuaría en mayor medida a la aparente ausencia de una modularidad en sentido estricto en lo concerniente a la organización de los componentes de la misma (y a la propia facultad del lenguaje en relación con la cognición), así como al cuadro que resulta del análisis genético del «órgano del lenguaje», según el cual (a) existirían multitud de genes implicados en la emergencia y el correcto funcionamiento de los centros neuronales responsables del procesamiento lingüístico (poligenismo); (b) el producto de cada gen actuaría, además, en diferentes momentos y en distintas regiones cerebrales durante el desarrollo (pleiotropismo); y (c) la contribución de los diferentes genes al fenotipo lingüístico sería limitada, condicionada a la de muchos otros genes y, por consiguiente, poco predecible (Benítez-Burraco 2007b);

d) Permitiría explicar de forma tan exacta como lo hace la teoría ortodoxa vigente actualmente todo tipo de fenómenos característicos del proceso de adquisición del lenguaje (cf. el caso de la adquisición de las preguntas $c u$ - en Garuseva y Thorton (2001), donde la generación de preguntas segmentadas no se explicaría necesariamente como un error en el establecimiento de determinados parámetros, sino como el resultado de la aplicación de un principio de economía natural, en la línea de lo sugerido por Chomsky 1995).

e) Finalmente, constituiría un marco teórico que permitiría dar cabida a factores de índole extrasintáctica (semánticos, pragmáticos, y, desde luego, cognitivos) en la caracterización del proceso de adquisición de los elementos constitutivos de la gramática, así como a la posibilidad de una relación más estrecha entre ellos. Esta circunstancia permitiría, 
en particular, incorporar de forma más precisa y justificada al modelo general de adquisición del lenguaje aquellos mecanismos generales de aprendizaje que, ciertamente, desempeñan un papel relevante durante el mismo, como se apuntó en el apartado 4.

\section{Conclusiones}

De todo lo discutido en este artículo parece concluirse que la gramática se configura como un sistema finito que define la capacidad lingüística de un sujeto determinado y que se encuentra representada en su cerebro (Anderson y Lightfoot 2000). Sin embargo, para entender adecuadamente la capacidad lingüística del ser humano, así como el proceso que permite su adquisición, parece necesario (a) desentrañar el programa genético responsable del desarrollo, el funcionamiento y la consolidación de los circuitos neuronales encargados del procesamiento lingüístico, acerca del cual ya existen algunas evidencias, obtenidas fundamentalmente a partir del análisis molecular de diversos trastornos del lenguaje de carácter hereditario (para una revisión, v. Benítez-Burraco 2004, 2007b); (b) poner en suspenso determinadas concepciones maximalistas acerca de la manera en que se produce el proceso de adquisición del lenguaje; (c) cuestionar una concepción demasiado restrictiva del modo en que el «órgano del lenguaje» se organiza anatómicamente y opera fisiológicamente, la cual ha buscado tradicionalmente delimitar de forma minuciosa las porciones del tejido cerebral dedicadas exclusivamente al procesamiento lingüístico, dejando a un lado la hipótesis más plausible, de que el lenguaje podría surgir realmente como consecuencia del desarrollo y el funcionamiento de un programa de interconexión único que relacionaría estructuras neuronales que no deberían concebirse como sistemas autónomos encargados del procesamiento de información exclusivamente lingüística, sino como subcomponentes de un mecanismo de computación que se emplearía en la resolución de tareas de muy diversos tipos; y (d) profundizar en la idea de que lo específico de dicho «órgano del lenguaje» no serían tanto sus componentes, como el conjunto en que se integran, y algo semejante podría afirmarse con relación a los genes responsables de su desarrollo y de su funcionamiento (las implicaciones en este sentido se desarrollan en Marcus 2004, 2006; y Benítez-Burraco 2007), así como al modo en que tiene lugar el propio proceso de adquisición del lenguaje.

\section{REFERENCIAS BIBLIOGRÁFICAS}

Anderson, S. R. (1993): «Linguistic expression and its relation to modality», en Coulter, G. R. (ed.), Phonetics and Phonology 3: Current Issues in ASL Phonology, San Diego, Academic. 
- y Lightfoot, D. W. (2000): «The human language faculty as an organ», Annual Review of Physiology 62, pp. 697-722.

Avital, E. y Jablonka, E. (2000): Animal Traditions. Behavioural Inheritance in Evolution, Cambridge, Cambridge University Press.

Bates, E. A., Thai, D. y Janowsky, J. (1992): «Early language development and its neural correlates», en Rapin, I. y Segalowitz, S. (eds.), Handbook of Neuropsychology, vol. 7, Child Neuropsychology, Amsterdam, Elsevier, pp.69-110.

- Thai, D., Turner, D., Fenson, J., Aram, D., Eisele, J. y Nass, R. (1997): «From first words to grammar in children with focal brain injury», Developmentl Neuropsychology 13, pp. 275-343.

Benítez Burraco, A. (2004): «Bases moleculares del lenguaje», en Nepomuceno Fernández, A., Salguero Lamillar, F. J. y Soler Toscano, F. (eds.), Bases biológicas, lingüísticas, lógicas y computacionales para la conceptualización de la mente, Sevilla, Mergablum. Edición y Comunicación. pp. 77-130

- (2005): «Caracterización neuroanatómica y neurofisiológica del lenguaje humano», Revista Española de Lingüistica 35, 2.

- (2007a): «Genes y lenguaje», Teorema 26, pp. 37-72.

- (2007b): «Aspectos genéticos del lenguaje», Revista Española de Lingüistica 37, pp. 103-137.

Ber WICK, R. C. (1985): The Acquisition of Syntactic Knowledge, Cambridge, MIT Press.

- (1998): «Language evolution and the minimalist program: The origins of syntax», en Hurford, J. R., Studdert-Kennedy, M. y Knight, C. (eds.), Approaches to the Evolution of Language, Cambridge, Cambridge University Press, pp. 299-304.

Bickerton, D. (1999): «How to acquire language without positive evidence: what acquisitionists can learn from creoles», en DeGraff, M. (ed.), Language Creation and Change: Creolization, Diachrony and Development, Cambridge, MIT Press.

Bloom, L., Hood, L. y Lightbown, P. (1974): «Imitation in language development: If, when, and why», Cognitive Psychology 6, pp. 380-420 .

Bloomfield, L. (1933): Language, Nueva York, Holt, Rinehart and Winston.

Bohannon, J. N. y Stanowicz, L. B. (1988): «The issue of negative evidence: adult responses to children's language errors», Developmentl Neuropsychology 24, pp. 684-689.

Brown, R. y Hanlon, C. (1970): «Derivational complexity and order of acquisition in child speech», en Hayes, J. R. (ed.), Cognition and the Development of Language, Nueva York, Wiley, pp.155-207.

Calvin, W. H. y Bickerton, D. (2000): Lingua ex machina. Reconciling Darwin and Chomsky with the Human Brain, Cambridge, MIT Press.

Cameron-Faulkner, T., Lieven, E. y Tomasello, M. ((2003): «A construction based analysis of child directed speech», Cognitive Science 27, pp. 843-873.

Сномsкy, N. A. (1957): Syntactic Structures, La Haya, Mouton.

- (1965): Aspects of the Theory of Syntax, Cambridge, MIT Press.

- (1975): Reflections on Language, Nueva York, Pantheon Books.

- (1980): Rules and Representations, Oxford, Basil Blackwell.

- (1986): Knowledge of Language: its Nature, Origin and Use, Nueva York, Prager.

- (1995): The Minimalist Program, Cambridge, MIT Press. 
- (2000): «Minimalist inquiries: the framework», en Martin, R., Michaels, D. y Uriagereka, J. (eds.), Step by Step. Papers in Minimalist Syntax in Honor of Howard Lasnik, Cambridge, MIT Press, pp. 89-155.

- (2001): Beyond Explanatory Adequacy, Cambridge, MIT Press.

- (2005): «Three factors in language design», Linguistic Inquiry 36, pp. 1-22.

ClaRK, E. (1987): «The principle of contrast: a constraint on language acquisition», en MacWhinney, B. (ed.), Mechanisms of Language Acquisition, Hillsdale, Erlbaum, pp. 1-34.

Colombo, J. y Bundy, R. (1983): «Infant response to auditory familiarity and novelty», Infant Behavior and Development 6, pp. 305-311.

Cormack, A. y Smith, N. (2002): «Compositionality, copy theory, and control», University College London Working Papers in Linguistics 14, pp. 355-375.

Crain, S. y Lillo-Martin, D. (1999): An Introduction to Linguistic Theory and Language Acquisition, Malden, Blackwell Publishers.

- y Pietroski, P. (2002): «Why language acquisition is a snap», The Linguistic Review (19, pp. 163-186.

- y Thorton, R. (1998): Investigations in Universal Grammar: a Guide to Experiments on the Acquisition of Syntax and Semantics, Cambridge, MIT Press.

Curtiss, S. (1977): Genie: a Psycholinguisitc Study of a Modern Day «Wild Child», Nueva York, Academic Press.

Damasio, H., Grabowski, T. J., Tranel, D., Hichwa, R. D. y Damasio, A. R. (1996): «A neural basis for lexical retrieval», Nature 300, pp. 499-505.

Deacon, T. W. (2000): «Evolutionary perspectives on language and brain plasticity», Journal of Comunication Disorders 33, pp. 273-291.

Deane, P. 1(992): Grammar in Mind and Brain: Explorations in Cognitive Syntax, La Haya, Mouton.

DeCasper, A. y Spence, M. (1986): «Prenatal maternal speech influences newborns' perception of speech sounds», Infant Behavior and Development 9, pp. 133-150.

Dehaene, S., Dupoux, E., Mehler, J., Cohen, L., Perani, D., van de MoorteLE, P. F., Lehbrici, S. y LE BihAN, D. (1997): «Anatomical variability in the cortical representation of first and second languages», Neuroreport 17, pp. 3809-3815.

Demetras, M. J., Post, K. N. y Snow, C. E. (1986): «Feedback to first language learners: the role of repetitions and clarification questions», Journal of Child Language 13, pp. 275-292.

Elman, J., Bates, E., Johnson, M., Karmiloff-Smith, A., Parisi, D. y Plunkett, K. (1997): Rethinking Innateness: a Connectionist Perspective on Development, Cambridge, MIT Press.

Fodor, J. A. (1983): The Modularity of Mind. An Essay on Faculty Psychology, Cambridge, MIT Press.

Fodor, J. D. (2001): «Setting syntactic parameters», en Baltin, M. y Collins, C. (eds.), The Handbook of Contemporary Syntactic Theory, Oxford, Blackwell, pp.730-767.

- y Crowther, C. (2002): «Understanding stimulus poverty arguments», The Linguistic Review 19, pp. 105-145.

Gavruseva, E. y Thornton, R. (2001): «Getting it right: acquisition of whosequestions in child english», Language Acquisition 9, pp. 229-267. 
Gibson, E. y WeXleR, K. (1994): «Triggers», Linguistic Inquiry 25, pp. 115-126.

Givón, T. (1979): On Understanding grammar, Nueva York, Academic Press.

Goldin-Meadow, S. y Mylander, C. (1990): «Beyond the input given: the child's role in the acquisition of language», Journal of Child Language 17, pp. 527-563.

Gould, T. D. y Gottesman, I. I. (2006): «Psychiatric endophenotypes and the development of valid animal models», Genes, Brain and Behavior 5, pp. 113119.

Greenfield, P. M. (1991): «Language, tools and brain: the ontogeny and phylogeny of hierarchically organized sequential behavior», The Behavior and Brain Sciences 14, pp. 531-577.

Guasti, M. T. (2002): Language Acquisition: the Growth of Grammar, Cambridge, MIT Press.

Hauser, M. D., Chomsky, N. y Fitch, W. T.(2002): «The faculty of language: what is it, who has it, and how did it evolve?», Science 298, pp. 1569-1579.

Hernández-Muela, S., Mulas, F. y Mattos, L. (2004): «Plasticidad neuronal funcional», Revista de Neurología 38, 1, pp. S58-S68.

Hesketh, S., Christophe, A. y Dehaene-Lambert, G. (1997): «Non-nutritivesucking and sentence processing», Infant Behavior and Development 20, pp. 263-269.

Hickok, G., Bellugi, U. y Klima, E. S. (1996): «The neurobiology of sign language and its implications for the neural basis of language», Nature 381, pp. 699-702.

Hirsh-Pasek, K., Treiman, R. y Schneiderman, M. (1984): «Brown and Hanlon revisited: Mothers' sensitivity to ungrammatical forms», Journal of Child Language 11, pp. 81-89.

Hornstein, N. y Lightfoot, D. (1981): «Introduction», en Hornstein, N. y Lightfoot, D. (eds.), Explanation in Linguistics: The Logical Problem of Language Acquisition, Londres, Longman, pp. 9-31.

Hubel, D. y Wiesel, T. (1962): «Receptive fields, binocular interaction and functional architecture in the cat's visual cortex», Journal of Physiology 160, pp. 106-54.

Jablonka, E. y Lamb, M. J. (2005): Evolution in Four Dimensions: Genetic, Epigenetic, Behavioral, and Symbolic Variation in the History of Life, Cambridge, MIT Press.

Johnson, M. H. (2003): «Development of human brain functions», Biological Psychiatry 54, pp. 1312-1316.

Kegl, J., Senghas, A. y Coppola, M. (1999): «Creation through contact: sign language emergence and sign language Change in Nicaragua», en DeGraff, M. (ed.), Language Creation and Language Change: Creolization, Diachrony, and Development, Cambridge, MIT Press, pp. 179-237.

Landau, B. y Gleitman, L. (1985): Language and Experience: Evidence From the Blind child, Cambridge, Harvard University Press.

Lefebvre, C. (1998): Creole Genesis and the Acquisition of Grammar, Cambridge, Cambridge University Press.

Lieberman, P. (2000): Human Language and Our reptilian Brain. The Subcortical Bases of Speech, Syntax and Thought, Cambridge, Harvard University Press.

Lieberman, P. (2002): «On the nature and evolution of the neural bases of human language», American Journal of Physical Anthropology 45, pp. 36-62. 
Lieven, E. (1994): «Crosslinguistic and crosscultural aspects of language addressed to children", en Gallway, C. y Richards, B. (eds.), Input and Interaction in Language Acquisition, Nueva York, Cambridge University Press, pp.56-73.

Lightfoot, D. (1982): «Review of Geoffrey Sampson, Making sense», Journal of Linguistics 18, pp. 426-431.

Locke, J. L. (1983): Phonological Acquisition and Change, Nueva York, Academic Press.

Longa, V. y Lorenzo, G. (2008): "What about a (really) minimalist theory of language acquisition?», Linguistics 46, pp. 541-570.

Lorenzo, G. (2007): El vacío sexual, la tautología natural y la promesa minimalista, Madrid, Visor.

- y LongA, V. (2003): «Minimizing the genes for grammar. The minimalist program as a biological framework for the study of language», Lingua 113, pp. $643-657$.

Lust, B. (2006): Child Language: Acquisition and Growth, Cambridge, Cambridge University Press.

Lust, B., Flynn, S., y Foley, C. (1996): «What children know about what they say: elicited imitation as a research method», en McDaniel, D., McKee, C. y Cairns, H. (eds.), Methods for Assessing Children's Syntax Cambridge, MIT Press, pp. 55-76.

Marcus, G. F. (1993): «Negative evidence in language acquisition», Cognition 46 , pp. 53-85.

Mayberry, R., Lock, E. y KAzmi, H. (2002): «Linguistic ability and early language exposure», Nature 417 , pp. 38.

Moerk, E. (1991): «Positive evidence for negative evidence», First Language 11, pp. 219-251.

Morgan, J., Bonamo, K. y Travis, L. (1995): «Negative evidence on negative evidence», Devalopmental Psychology 31, pp. 180-197.

Müller, R. A., Behen, M. E., Rothermel, R. D., Muzik, O., Chakraborty, P. K. y Chugani, H. T. (1999): «Brain organization for language in children, adolescents, and adults with left hemisphere lesion: a PET study», Progress Neuropsychopharmacology and Biological Psychiatry 23, pp. 657-668.

Neville, H. J., Bavelier, D., Corina, D., Rauschecker, J., Karni, A., Lalwani, A., Braun, A., Clark, V., Jezzard, P. y Turner, R. (1998): «Cerebral organization for language in deaf and hearing subjects: biological constraints and effects of experience», Proceeding of the National Academy of Sciences United States of America 95, pp. 922-929.

Newmeyer, F. J. (1997): «Genetic dysphasia and linguistic theory», Journal Neurolinguistics 10 , pp. 47-73.

- (2003: «Grammar is grammar and usage is usage», Language 79, pp. 682707.

NEwPORT, E. L. (1977): «Motherese: the speech of mothers to young children», en Castellan, N. J., Pisoni, D. B. y Potts, G. R. (eds.), Cognitive Theory, vol. II Hillsdale, Lawrence Erlbaum, pp.177-217.

Nobre, A. C. y Plunkettt, K. (1997): «The neural system of language: structure and development», Current Opinion on Neurobiology 7, pp. 262-266.

O'Grady, W. (2003): "The radical middle: nativism without Universal Grammar», en Doughty, C. J. y Long, M. H. (eds.), Handbook of Second Language Acquisition, Malden, Blackwell, pp. 43-62. 
Piatelli-Palmarini, M. (1989): «Evolution, selection, and cognition: from «learning» to parameter setting in biology and the study of language», Cognition 31, pp. 1-44.

Pinker, S. (2001): El instinto del lenguaje, Madrid, Alianza Editorial.

Post, K. (1994): «Negative evidence in the language learning environment of later-borns in a rural Florida community», en Sokolov, J. y Snow, C. (eds.), Handbook of Research in Language Development Using CHILDES, Hillsdale, Erlbaum, pp. 132-173.

Pullum, G. K. (1996): «Learnability, hyperleaming, and the poverty of the simulus», en Johnson, J., Juge, M. L. y Moxley, J. L. (eds.), Proceedings of the Twenty-Second Annual Meeting of the Berkeley Linguistics Society, Berkeley, Berkeley Linguistics Society.

— y Scholz, B. C. (2002): «Empirical assessment of stimulus poverty arguments», The Linguistic Review 19, pp. 9-50.

Purvis, K. L. y Tannock, R. (1997): «Language abilities in children with attention deficit hyperactivity disorder, reading disabilities, and normal controls», Journal of Abnormal Child Psychology 25, pp. 133-144.

Ramus, F. (2006): «Genes, brain, and cognition: a roadmap for the cognitive scientist», Cognition 101, pp. 247-269.

RitTer, N. A. (2002): «Introduction», The Linguistic Review 19, pp. 1-7

SAfrRAN, J. R., Aslin, R. N. y Newport, E. L. (1996: «Statistical learning by 8-month-old infants», Science 274, pp. 1926-1928.

Saxton, M. (1997): «The Contrast Theory of negative evidence», Journal of Child Language 24, pp. 139-161.

- (1998: Negative evidence and negative feedback: immediate effects on the grammaticality of child speech, Manuscrito no publicado, Royal Holloway, Universidad de Londres.

— Kulscar, B., Marshall, G. y Rupra, M. (1998): «Longer-term effects of corrective input: an experimental approach», Journal of Child Language 25, pp. 701-721.

Schacter, J. (1990): "On the issue of of completeness in second language acquisition», Second Language Research 6, pp. 93-124.

SeidenberG, M. S. y MacDonald, M. C. (1999): «A probabilistic constraints approach to language acquisition and processing», Cognitive Science 23, pp. 569-588.

Senghas, A. (1995): «The development of nicaraguan sign language via the language acquisition process», en MacLaughlin, D. y McEwen, S. (eds.), Proceedings of the 19th Annual Boston University Conference on Language Development, Boston, Cascadilla Press, pp. 543-552.

Singleton, J. L., Morford, J. P. y Goldin-Meadow, S. (1993): «Once is not enough: standards of well-formedness in manual communication created over three different timespans», Language 69, pp. 683-715

Smith, N. (2002): Language, Bananas, and Bonobos: Linguistic Problems, Puzzles, and Polemics, Oxford, Oxford University Press.

Snow, C. E. y Ferguson, C. A. (1977): Talking to Children: Language Input and Acquisition, Cambridge, Cambridge University Press.

Stich, S. (1975): Innate Ideas, Berkeley, University of California Press.

Strapp, C. (1999): «Mothers', fathers', and siblings' responses to children's 
language errors: Comparing sources of negative evidence», Journal of Child Language 26, pp. 373-391.

Thomas, C., Altenmilller, E., Marchmann, G., Kahrs, J. y Dichgans, J. (1997): «Language processing in aphasia: changes in lateralization patterns during recovery reflect cerebral plasticity in adults», Electroencephalography and Clinical Neurophysiology 102, pp. 86-97.

Winterer, G. y GoldMAn, D. (2003): «Genetics of human prefrontal function», Brain Research Reviews 43, pp. 134-163. 
